\title{
Evaporation from coal mine pit lakes: measurements and modelling
}

D McJannet Commonwealth Scientific and Industrial Research Organisation, Australia

A Hawdon Commonwealth Scientific and Industrial Research Organisation, Australia

B Baker Commonwealth Scientific and Industrial Research Organisation, Australia

K Ahwang Commonwealth Scientific and Industrial Research Organisation, Australia

J Gallant Commonwealth Scientific and Industrial Research Organisation, Australia

S Henderson BHP, Australia

A Hocking $B H P$, Australia

\begin{abstract}
Open cut coal mines can have large surface water catchments and often extend to depths below the natural water table level with constant dewatering required to maintain coal extraction. When mining ceases, surface water runoff and groundwater start to fill the void, and pit lakes form. Understanding the hydrological and chemical evolution of these lakes is important for appropriate closure planning. One of the key processes controlling pit lake evolution is evaporation loss, and current estimates of this process are highly uncertain. Recognising the importance of evaporation and the uncertainty in current estimation methods, the Commonwealth Scientific and Industrial Research Organisation (CSIRO) has been working in conjunction with BHP to measure and model evaporation from pit lake environments at Norwich Park Mine, a large open cut coal mine in Central Queensland.
\end{abstract}

Compared with typical lakes and reservoirs, pit lakes are a unique environment because of the depth to the water surface below the original land surface. The water surface in a pit is likely to be sheltered from winds experienced at the land surface, and the steep pit walls can shade the water body within. Based on a number of evaporation studies in pit lake environments, CSIRO has developed a pit lake evaporation model that can be run using readily available data sources, but this model is yet to be tested in a coal mine environment. Open cut coal mines in Central Queensland are typically strip mined, resulting in long, rectangular, box-shaped voids. The aim of this study was to measure evaporation in a pit lake at Norwich Park Mine and to use the results to test the performance of the pit lake evaporation model. In addition, the measurement dataset was used to test the performance of the pan coefficient evaporation-modelling approach, which is commonly used in the mining industry for specifying evaporation from pit lakes.

Successful measurements were collected over a six-month period using a custom-built floating evaporation monitoring system, and this data was used as the baseline dataset against which to test the performance of two evaporation-modelling approaches. Despite its widespread use, the pan coefficient model was shown to be a very poor predictor of daily evaporation. The CSIRO pit lake evaporation model showed the same trends as daily evaporation measurements, but the model consistently tended to underestimate evaporation totals. Further investigations showed that the wind speed scaling procedure utilised in the model for reducing wind speed at land surface level to that at water level was not suitable for coal mine pits. Observations showed that wind speeds at pit level at the study location were actually greater than those at land level. It is suspected that the long, narrow shape of the coal pits acts to funnel wind flow into the pit, thereby, resulting in an acceleration of airflow.

When appropriate wind speed scaling was applied, the CSIRO pit lake model performance was excellent. Total predicted evaporation was within $5 \%$ of that measured, and daily trends were very well predicted. 
These results give confidence in achieving reliable evaporation estimates once modified wind speed scaling approaches can be defined for coal mine environments. This task is now the focus of field investigations at Norwich Park Mine.

Keywords: evaporation, pit lake, measurements, modelling

\section{Introduction}

Pit lakes often form after open cut mining activities cease. The mined void can fill with water from surface and sub-surface sources, and once they do, a complex series of interactions between hydrological and geochemical processes takes place. If not managed correctly, these interactions have the potential to result in negative environmental impacts (Johnson \& Wright 2003). The rate of evaporation from these pit lakes -in combination with the composition of surrounding rock, oxygen content, $\mathrm{pH}$ status, biological activity and flux of water-controls the chemistry of the evolving pit lake.

Evaporation is important in pit lake evolution primarily for its influence on the standing water level but also because it acts to concentrate various constituents and changes the thermal character of the water body. A concern regarding pit lakes is the movement of concentrated constituents, particularly salts, to the surrounding surface water and groundwater environments. From a mine management perspective, there is a need for reliable estimates of evaporation for these water bodies, but in general, evaporation from pit lakes is very poorly understood. Recent research by the Commonwealth Scientific and Industrial Research Organisation (CSIRO) in collaboration with mining industry partners is helping to rectify this problem.

Recognising the importance of better understanding of evaporation from pit lakes, BHP Billiton Iron Ore commissioned CSIRO to undertake early field measurements and modelling experiments at both the Mount Goldsworthy and Nimingarra mines in the Pilbara area of Western Australia, with the overall aim of developing a model of pit lake evaporation that could be used for existing pit lakes and for those likely to evolve in the future. Since this initial work, BHP Coal Pty Ltd recognised the benefits to be gained through improved evaporation estimates and engaged CSIRO to determine whether the pit lake evaporation model would provide reliable estimates in coal mine environments. Pit lakes in BHP coal mining operations in the Bowen Basin tend to be long and narrow because of the cut-and-fill type approach used in coal extraction operations, and the effect of this different topographic configuration on evaporation was unknown. To test, and potentially improve, the model's performance, CSIRO commenced measurements and modelling experiments at Norwich Park Mine in the Bowen Basin area of Central Queensland, Australia. The study commenced in September 2018 and will continue for a 12-month period. This paper reports on the first six months of measurements from this project. The main aims of this study were:

- To measure evaporation rates from a coal mine pit lake, using state-of-the-art instrumentation.

- To test existing pit lake evaporation model performance, using measurement data.

\section{The unique evaporation environment of a mine void}

When compared with lakes and reservoirs, pit lakes are a unique environment for evaporation because of the depth to the water surface from the original land surface. In addition to the physical characteristics of the pit, the chemical evolution of a pit lake may also exert control on evaporation rates. Any attempt to model pit lake evaporation should be mindful of the unique characteristics of a mine pit.

Solar radiation input is a key driver of evaporation from lakes, but in a pit lake environment the steep walls can cause shading of the water surface (McJannet et al. 2017). The height of the pit walls and the dimensions and orientation of the pit will dictate how much solar radiation the lake receives; as such, shading is an important consideration in any estimates of pit lake evaporation. A changing lake level as the pit lake evolves will also impact upon shading and needs to be taken into account in long-term studies of pit lake evolution. 
Wind speed also exerts a strong influence on evaporation, and the unique environment of a pit lake complicates attempts to model evaporation using land-based wind speed data. Wind speed data collected on the land surface should ideally be adjusted to account for the sheltering effects of the mine pit. Pit lake sheltering will depend on local topography and pit depth, dimensions and orientation relative to the prevailing wind.

The salinity of a water body is known to affect the rate of evaporation because of the effect of salts on saturation vapour pressure (Calder \& Neal 1984; Oroud 1995; Panin \& Brezgunov 2007). Saturation vapour pressure represents the ability of air to carry water vapour. In general, the higher the salinity of the water, the lower the rate of evaporation. Salinity levels in pit lakes are influenced by the salinity of the groundwater or pumped inputs, the local geology and the concentrating effect of evaporation; as such, any model should be capable of accounting for such effects.

\section{Site description}

Norwich Park Mine is an open cut coal mine in Central Queensland, Australia. Currently, no mining activities are taking place onsite; however, routine site maintenance, rehabilitation and onsite water management activities continue. During active mining, the pits generally migrated in an easterly direction as coal was extracted, leaving a series of elongated pits (Figure 1). These pits typically have steep walls on the northeast- to east-facing side and overburden piles on the southwest to west side (Figure 2). Many of the pits at Norwich Park Mine have filled with water since extractive processes ceased, and understanding the evaporation from these pit lakes is the focus of this study.

The location of Gilbert R6, which is the focus site for evaporation measurements, is shown in Figure 1. A weather station was installed at the top of Gilbert R6 to represent meteorological conditions over the land surface in this area. The pit lake is approximately $65 \mathrm{~m}$ below the original land surface, and the pit lake has a surface area approximately 9.5 ha.

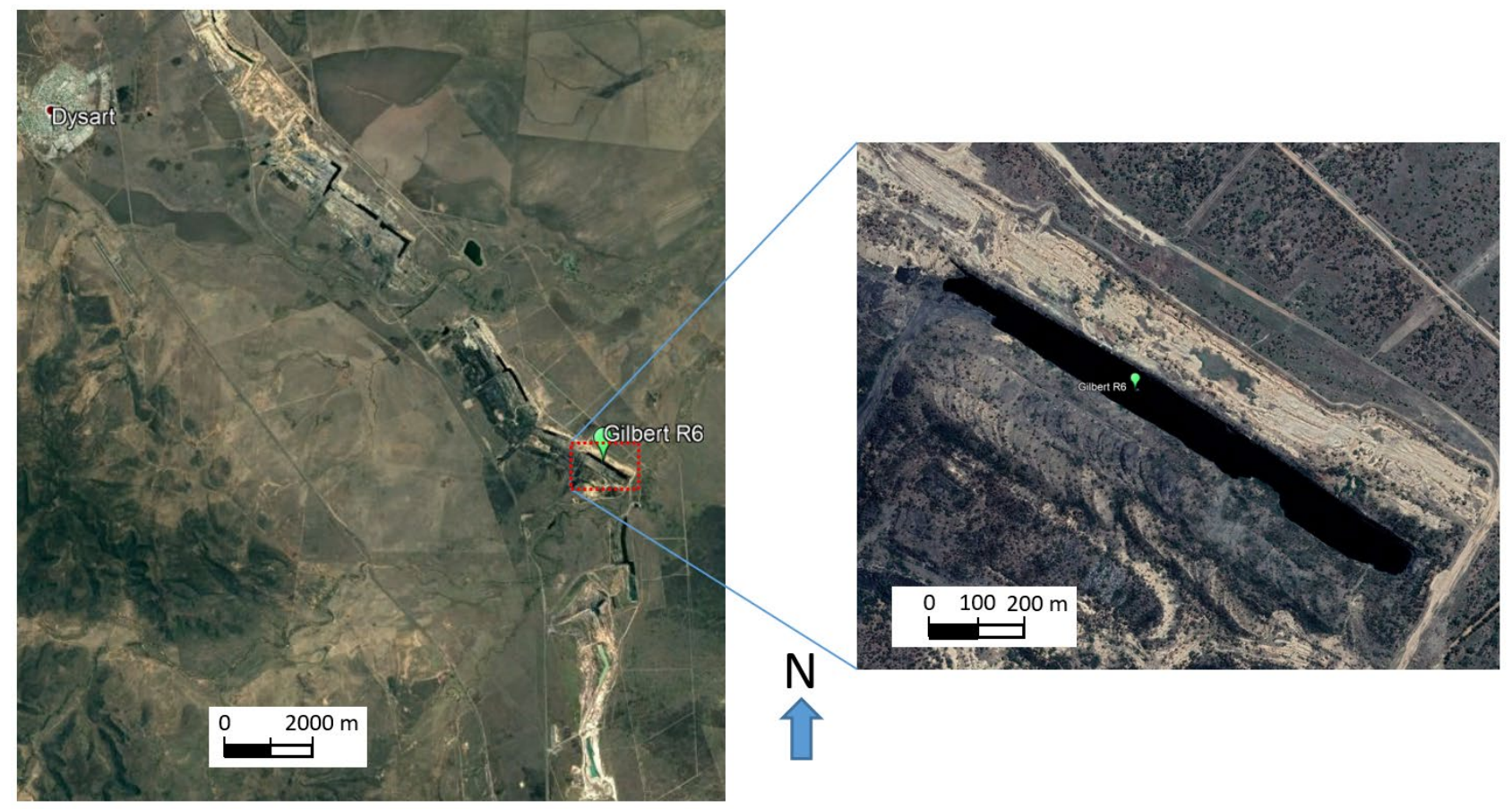

Figure 1 Norwich Park Mine showing pit lakes (left panel) and a more detailed view of the Gilbert R6 pit (right panel), which is the focus of this study. Image source: Google Earth 2018, Digital Globe 2019 and CNES/Airbus 2019 


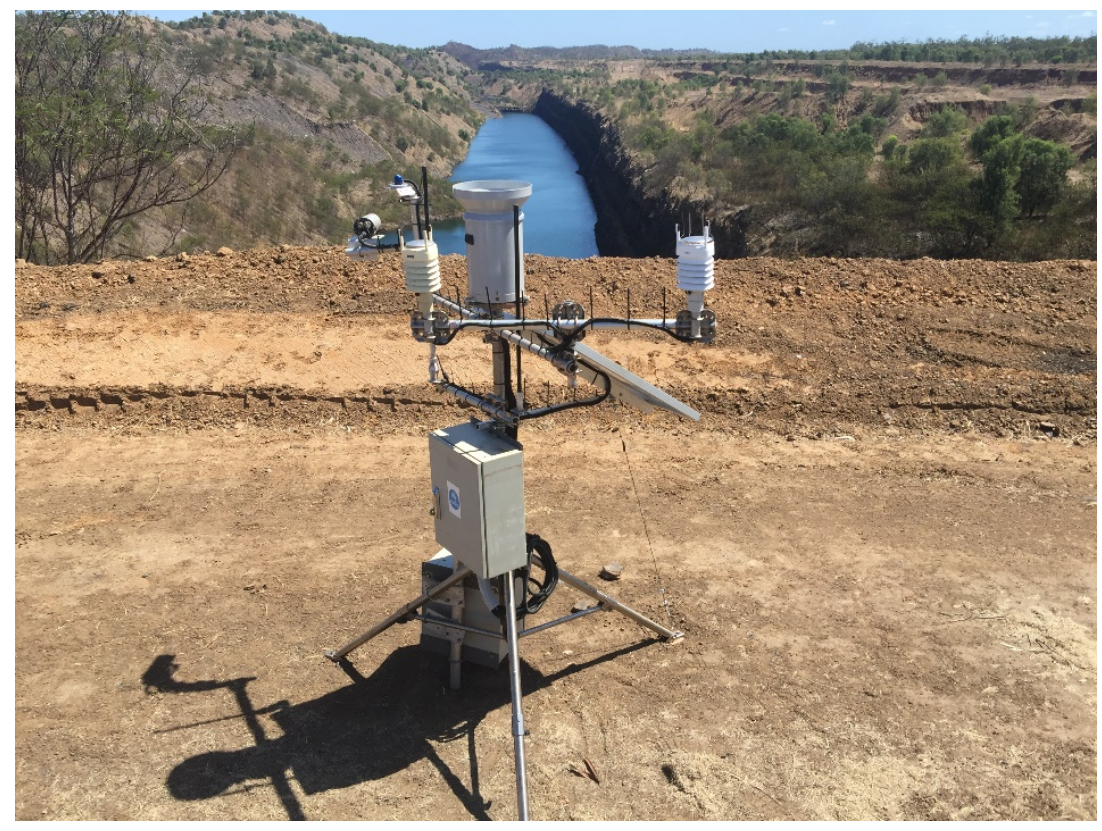

Figure 2 Weather station located at the top of Gilbert R6. This weather station records meteorological observations representative of those at land surface level

\section{$4 \quad$ Measurement methods}

\subsection{Land surface weather station}

A weather station was installed at the end of Gilbert R6 to collect meteorological observations representative of the surrounding land surface (Figure 2). Observations included rainfall, wind speed and direction, temperature, humidity and solar radiation. The weather station also has a remote camera for monitoring the evaporation measurement equipment deployed on the lake. The weather station also provided a radio link to the floating evaporation pan so that data could be collected remotely using $3 \mathrm{G}$ telemetry.

\subsection{Floating evaporation pan}

A pit lake environment presents a significant challenge to evaporation measurements because widely used micrometeorological techniques such as eddy covariance are not suitable. Such techniques are suited to determination of fluxes over large, flat surfaces with well evolved boundary layers and homogenous airflow (Munger et al. 2012). In a pit lake, the water surface is flat but may not extend far, and the airflow is highly complex because of flow distortion over the pit walls. This, combined with issues around floating and anchoring an eddy covariance system in the middle of a water body, means that alternative approaches are required. To address these issues, CSIRO designed a set of evaporation monitoring equipment that consisted of a floating evaporation pan contained within a large floating PVC pipe frame, known as the 'wave splitter' (Figure 3). The wave splitter acted to deflect the waves and direct energy away from the pan, thereby increasing data retention. A block anchor was set in place, with mooring lines up to a surface float. The floating pan rotated around the anchoring point in response to prevailing winds. 


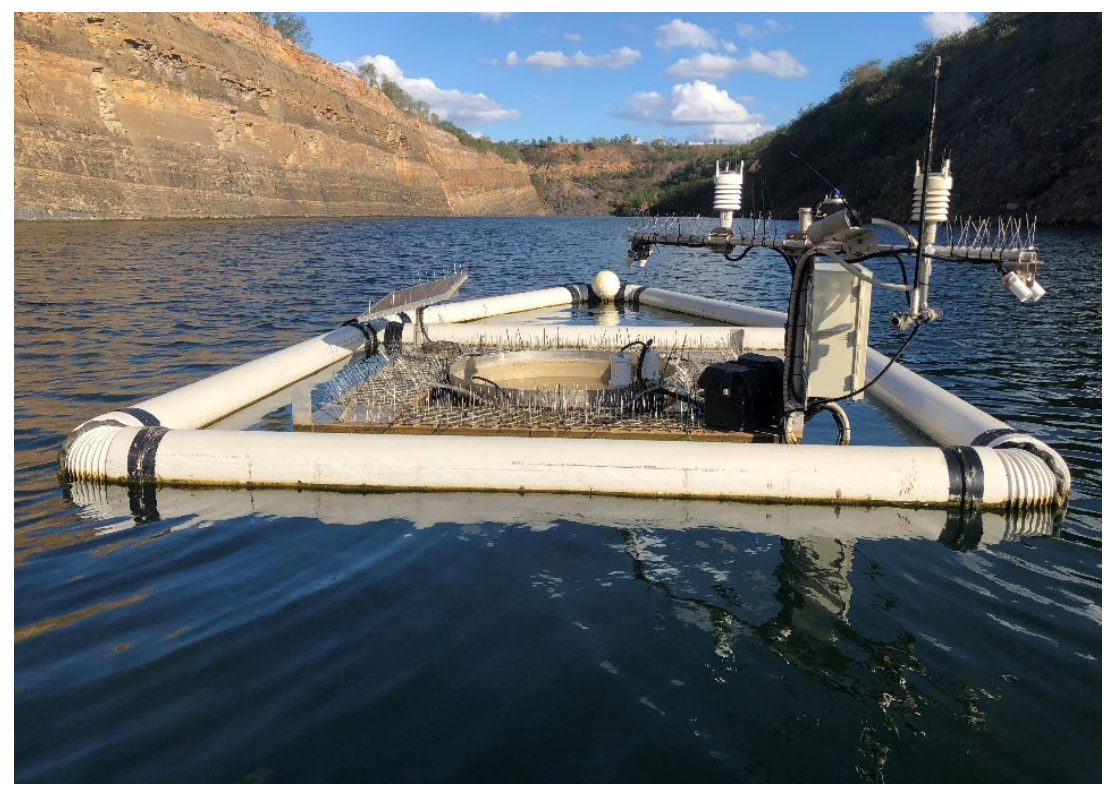

Figure 3 Floating evaporation pan deployed on the pit lake surface at Gilbert R6

The aluminium evaporation pan was $1,200 \mathrm{~mm}$ in diameter and $250 \mathrm{~mm}$ deep. The pan was housed within a surrounding frame, which also provided mounting locations for a solar panel, datalogger and other sensors. The pan was filled with water from the lake to within $70 \mathrm{~mm}$ of the lip of the pan. The pan was immersed in the pit lake to minimise differences in water temperature when compared with the surrounding water. The monitoring and filling of the evaporation pan was fully automated, with any evaporated water being replenished at midnight each day using an immersed pump. A second pump was installed inside the pan to enable lowering of the water level in situations where too much water was in the pan (e.g. rain, remote purging and wave action). The water level in the pan was measured with two high accuracy and precision magnetostrictive linear-positioning sensors (GH-Series, MTS Sensors, USA). The level sensors were installed within a stilling well to further minimise wave action.

Supplementary measurements of air temperature, relative humidity, wind speed, atmospheric pressure and rainfall were made at a height of $1.0 \mathrm{~m}$ above the water. To ensure that conditions within the pan did not deviate too greatly from those in the pit lake, sensors were installed to measure the lake and pan water surface temperature. Lake and pan water surface temperature measurements were also duplicated for redundancy.

The immersed pan evaporation $\left(E_{\mathrm{pan}}\right)$ was calculated for each 24-hour period by subtracting water depth at the end of the measurement period from depth recorded at the start of the measurement period. Immersed pan evaporation was converted to pit lake evaporation $\left(E_{\text {lake }}\right)$ using a correction factor that adjusts for any differences in temperature of water in the pan relative to the surrounding lake (McJannet et al. 2017). This approach relies on the fact that the meteorological conditions (i.e. temperature, humidity, wind speed, radiation) experienced by the lake and by the pan are essentially the same and that the differences in evaporation are related only to differences in the surface temperature of the two evaporating surfaces. Lake evaporation is calculated from immersed pan evaporation using the following equation:

$$
E_{\text {lake }}=E_{\mathrm{pan}} \frac{\left(e_{\text {lake }}^{*}-e_{\mathrm{air}}\right)}{\left(e_{\mathrm{pan}}^{*}-e_{\mathrm{air}}\right)}
$$

where:

$$
\begin{aligned}
& e_{\text {lake }}^{*}=\text { the saturated vapour pressure }(\mathrm{kPa}) \text { at the water surface temperature of the lake. } \\
& e_{\text {pan }}^{*}=\text { the saturated vapour pressure }(\mathrm{kPa}) \text { at the water surface temperature of the pan. } \\
& e_{\text {air }}=\text { the vapour pressure }(\mathrm{kPa}) \text { of the air. }
\end{aligned}
$$




\section{$5 \quad$ Modelling methods}

Methods to routinely estimate evaporation from a pit lake need to be based on readily available datasets that can be used to represent conditions that control evaporation. Typically, such models must utilise land-based meteorological data, such as that collected by the Bureau of Meteorology at many locations around Australia.

Two modelling methods will be described in this section: the pan coefficient approach and the CSIRO pit lake evaporation model. Due to data sources being readily available, the pan coefficient approach is commonly used in the mining industry to estimate evaporation. The CSIRO pit lake evaporation model has been developed over the last few years to try to account for the unique evaporation environment of a pit lake while still being able to be run on readily available datasets.

\subsection{Pan coefficient model}

The pan coefficient model is arguably the most common approach to estimating evaporation from water bodies because of its simplicity and minimal data requirements. Pan coefficient evaporation is derived by multiplying Class A pan evaporation by a constant factor (or coefficient). Using the pan coefficient technique, lake evaporation, $E_{\text {lake }}(\mathrm{mm} / \mathrm{d})$, is given by:

$$
E_{\text {lake }}=E_{\text {classA }} \cdot K_{\text {pan }}
$$

where:

$$
\begin{aligned}
E_{\text {classA }}= & \text { evaporation }(\mathrm{mm} / \mathrm{d}) \text { as measured by a standard Class A evaporation pan located on the } \\
& \text { land surface. } \\
K_{\text {pan }}= & \text { the so-called pan coefficient, which converts pan evaporation to water body } \\
& \text { evaporation. }
\end{aligned}
$$

Pan evaporation measurements in Australia usually only occur at intensive monitoring sites maintained by the Bureau of Meteorology. For this study, the nearest Class A pan to Norwich Park Mine is at Moranbah Airport (034035), which is approximately $80 \mathrm{~km}$ north-northwest of Norwich Park. A commonly used $K_{\text {pan }}$ is 0.7; however, there seems to be no substantiated argument for the use of this value, which is likely to have been originally derived from studies of very large lakes in North America many years ago (Kohler 1952). A number of studies of pit lake evaporation in Australia use modelling approaches that employ the pan coefficient model with a $K_{\text {pan }}$ of 0.7 (e.g. Sivapalan 2005; Worley Parsons 2013; Zhan 2006).

\subsection{CSIRO pit lake evaporation model}

The pit lake evaporation model built by CSIRO runs using land surface meteorological observations, which have been collected at locations as close as possible to the mine pit. The evaporation model uses aerodynamic principles originally proposed by Dalton (1802) to calculate evaporation from a pit lake $\left(E_{\text {lake }}\right)$ :

$$
E_{\text {lake }}=f\left(U_{1}\right)\left(e_{\text {lake }}^{*}-e_{\text {air }}\right)
$$

where:

$$
\begin{aligned}
f\left(U_{1}\right)= & \text { a wind function, which describes the diffusion mechanism by which thermal energy is } \\
& \text { removed from the surface as vapour }(\mathrm{mm} / \mathrm{kPa} / \mathrm{d}) \text {, and other variables are described } \\
& \text { above. }
\end{aligned}
$$

An important factor in accurately specifying lake evaporation using aerodynamic approaches is making an estimate of water temperature when it is not directly measured. The CSIRO pit lake model predicts water temperature using 'equilibrium temperature' concepts. The idea of equilibrium temperature was first put forward by Edinger et al. (1968) and has since been used by numerous researchers (De Bruin 1982; Finch 2001; Keijman 1974). The equilibrium temperature approach allows water temperature to be estimated as 
a function of time and water depth (Finch 2001). The equilibrium temperature model requires standard over-land meteorological measurements to run. Those interested in more-detailed calculation methods are directed to McJannet et al. (2013).

The meteorological measurements required to run the transferrable pit lake evaporation model are average daily air temperature, vapour pressure (calculated from temperature and humidity observations), solar radiation and wind speed-all measured above land. In this study, this data was collected by the land surface weather station. Before solar radiation and wind speed can be used for pit lake applications, they need to be scaled to reflect the shading and sheltering effects that were discussed in Section 2.

Solar radiation data from land surface observations were scaled to pit lake level using the solar radiation (SRAD) model (Moore 1992; Wilson \& Gallant 2000). SRAD calculates potential solar radiation received by a surface as a function of latitude, slope, aspect, topographic shading and time of year. Using a digital elevation model of the pit of interest, the SRAD model can account for variations in topographic shading throughout the year. This makes the SRAD model well suited to mine pit applications where digital elevation models are most likely available for site-specific analysis. For the Norwich Park Mine study, a digital elevation model with a resolution of $5 \mathrm{~m}$ was used for SRAD analysis. At Norwich Park Mine, the average daily shortwave radiation ratio (SWRR) was calculated for the entire pit lake surface. SWRR is the ratio of the total daily solar radiation input on the pit lake surface compared with that for an unshaded horizontal surface at this location. The observed total daily solar radiation was multiplied by the SWRR for the pit lake, before use in the model.

The SWRR for each pixel on the fifteenth day of the middle month of each season is shown in Figure 4. Shading effects are most pronounced along the highwall of the pit lake because of the angle of the sun relative to pit orientation. Shading effects are smallest when the sun is nearly directly overhead during summer (January) and largest during winter (July) when the sun is furthest north. The daily pit lake average SWRR for Gilbert Ramp 6 was at a minimum of 0.77 during June (equivalent to solar radiation input reduction of $23 \%$ ) and peaked in December at 0.97 when the sun was directly overhead (equivalent to solar radiation input reduction of $3 \%)$.

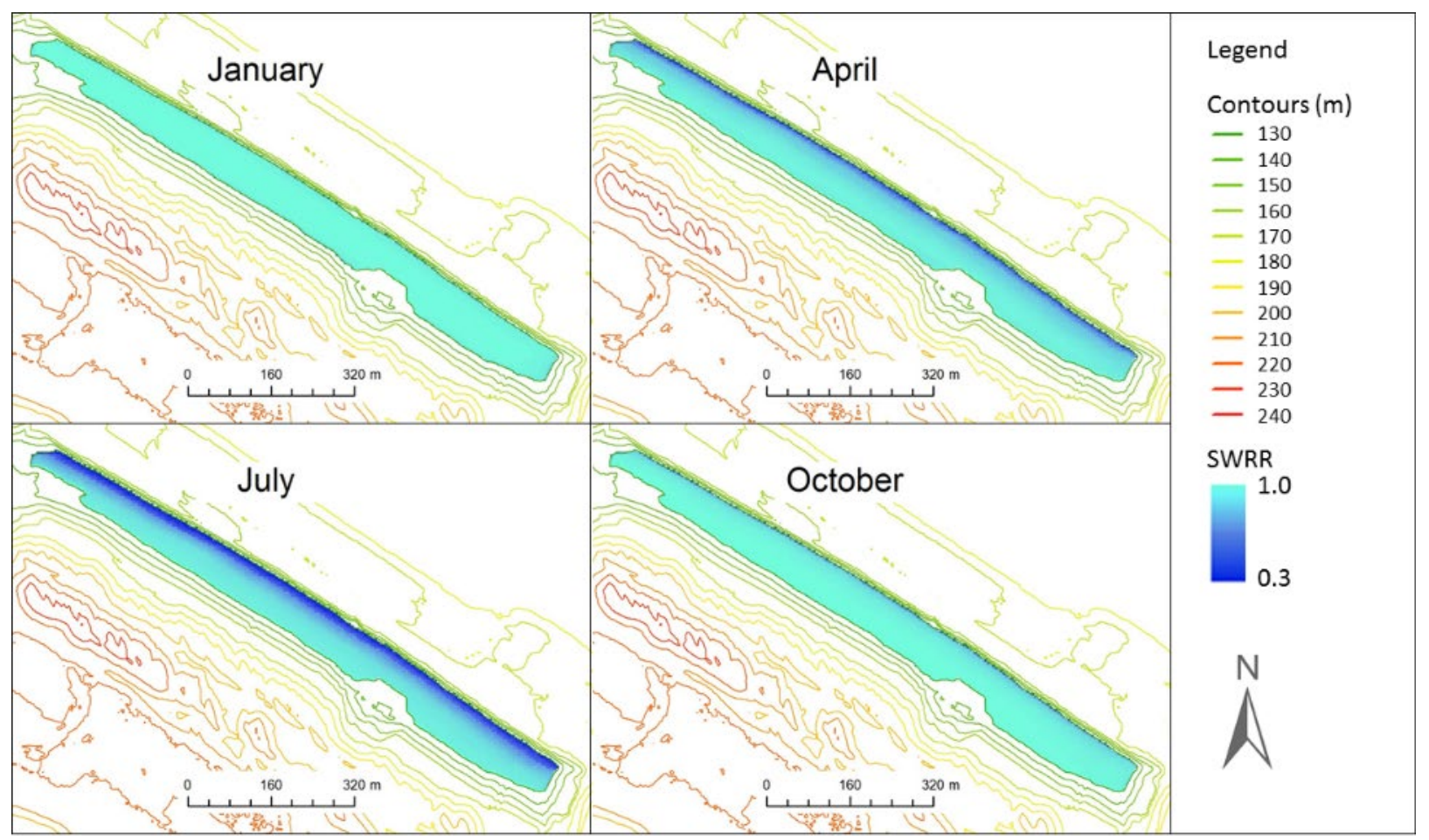

Figure 4 Spatial distribution of SWRR across the pit lake surface on the 15th day of the middle month of each season at current water levels 
Based on observations from four previous pit lake studies, we have derived a simple exponential decay relationship to enable us to estimate the sheltering effect of the pit walls based on the depth of the pit lake below the surrounding landscape and the average fetch across the water body. The relationship is based on field observations, and the scaling factor derived is applied to measured wind speed data before it is used in any modelling. An evaporative wind function for the pit lake, $f\left(U_{1}\right)$, was also defined by McJannet et al. (2017) using data from six evaporation studies. The function is based on the depth of the pit lake below the surrounding landscape and the average fetch across the water body in the direction of the prevailing wind. This wind function effectively accounts for the turbulence experienced at a pit lake due to the pit shape. The wind function has the following form:

$$
f\left(U_{1}\right)=a+\left(b\left(\frac{h}{F}\right)+c\right) U_{1}
$$

where:

$$
\begin{array}{ll}
h= & \text { the pit lake depth below the surrounding land surface (Gilbert R6 }=65 \mathrm{~m} \text { ). } \\
= & \text { the distance across the pit lake in the direction of predominant winds } \\
& \text { (Gilbert } \mathrm{R} 6=325 \mathrm{~m} \text { ). } \\
a, b \text { and } c= & \text { unpublished coefficients. } \\
U_{1}= & \text { the wind speed measured at } 1 \mathrm{~m} \text { above the water surface. }
\end{array}
$$

The evaporation rate also needs to be adjusted for the salinity of the water body, as salinity is known to affect the rate of evaporation because of the effect of the salts on the saturation vapour pressure (Calder $\&$ Neal 1984; Oroud 1995; Panin \& Brezgunov 2007). To consider the likely impact of salinity on evaporation, the relationship defined by Panin \& Brezgunov (2007) was used. The salinity level in the Norwich Park Mine pit $(10 \mathrm{mS} / \mathrm{cm})$ results in just a $1 \%$ reduction in evaporation rate.

\section{Results and discussion}

\subsection{Evaporation measurements}

Over the 182 days of the study period, evaporation was successfully measured on 142 days (78\% measurement success rate). Evaporation measurements were excluded during periods of rain, strong wave action and equipment maintenance. In order to produce a complete record of daily evaporation, data gaps were filled using a simple aerodynamic modelling approach (Equation 3), which utilised meteorological observations made from the floating pan in order to approximate evaporation. Successful measurement days were used to specify model parameters and define a site-specific wind function. We note here that this wind function is different from that specified in Equation 4, as the wind function in Equation 4 is generally applicable to any pit lake where lake dimensions are known, whereas the site-specific wind function only applies to Gilbert R6 at current water level. Correlation between measured evaporation and evaporation predicted with the aerodynamic model was very high, $R^{2}=0.96$, and the standard error of model estimates was just $0.5 \mathrm{~mm} / \mathrm{d}$. This gives a high level of confidence in modelled evaporation rates for those days for which evaporation measurements could not be used.

Figure 5 shows daily evaporation measured at Gilbert R6 for the six-month study period as blue bars; modelled values, which are used to fill the periods when evaporation measurements could not be utilised, are shown as orange bars. Over this period, the average daily evaporation rate was $8.3 \mathrm{~mm}$, and total evaporation was $1,505 \mathrm{~mm}$. The highest daily evaporation total was $17.6 \mathrm{~mm}$. These evaporation rates are high by international standards and reflect the hot and arid conditions experienced in this part of Australia. The evaporation rates shown in Figure 5 will be used as the baseline dataset, which will be used to test the performance of alternative modelling approaches in the following sections. 


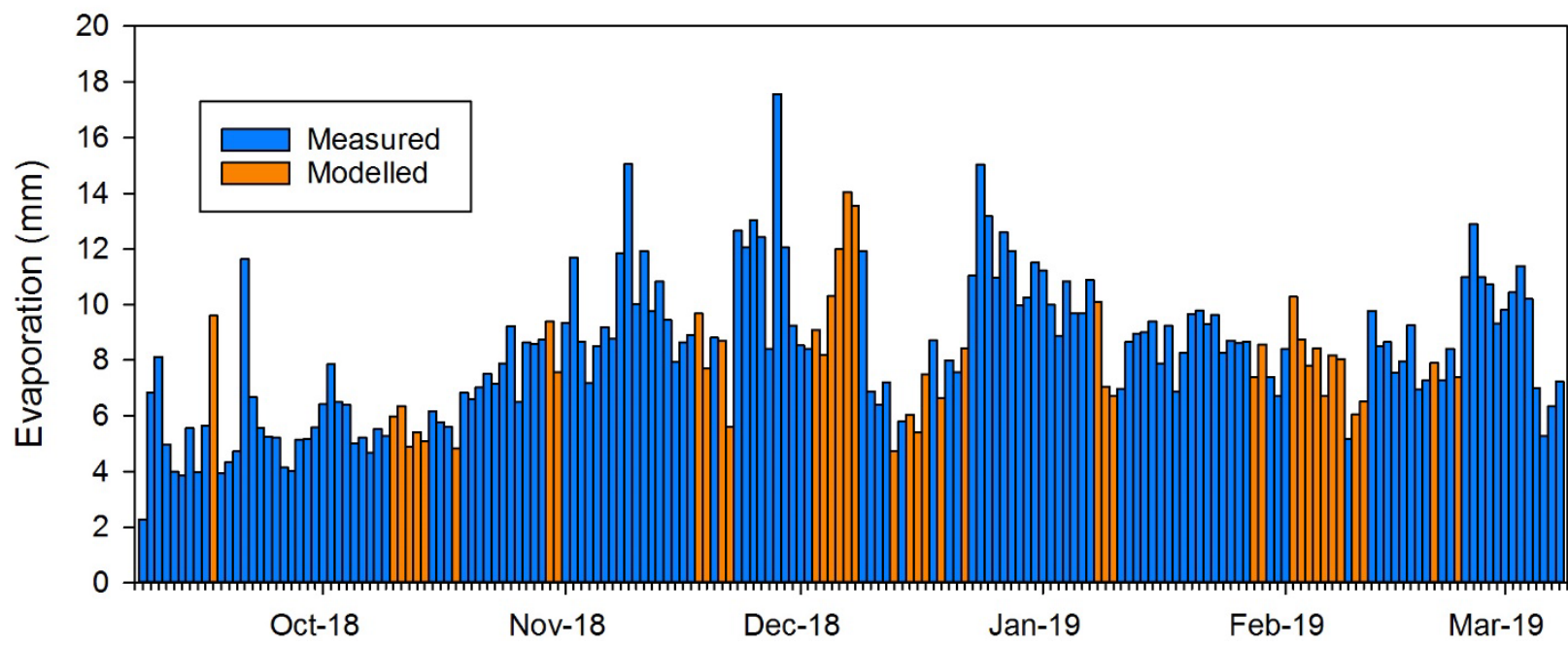

Figure 5 Daily evaporation rates from Gilbert R6 for a six-month period between September 2018 and March 2019. Blue bars represent measured days, and the orange bars represent days filled using relationships with meteorological variables measured over the water surface

\subsection{Pan coefficient model}

A comparison of a time series of daily pit lake evaporation measurements and evaporation estimated using the pan coefficient approach with a coefficient of 0.7 is shown in Figure 6(a). From this figure, it can be seen that the pan coefficient approach typically underestimates measured evaporation and often does not even replicate seasonal variations. Over the six-month period, the pan coefficient approach produced a total evaporation loss of $971 \mathrm{~mm}$, which is $36 \%$ less than that measured onsite at Gilbert R6.

A scatter plot of daily measured evaporation against daily evaporation estimated using the pan coefficient approach also reveals that the estimates are not highly correlated $\left(R^{2}=0.20\right.$; Figure $\left.6(b)\right)$. It is likely that some of the difference among daily estimates comes from the fact that the pan coefficient approach is unable to adequately account for heat storage effects. A large body of water can act like a battery absorbing heat during the day and slowly releasing it throughout the night. The pan coefficient that gives the best approximation of total measured evaporation for the six-month study period was 1.1; however, on a monthly timescale, the pan coefficient ranged between 0.8 and 1.2. With such variation in pan coefficients, any estimates made using this technique should be regarded as highly uncertain.
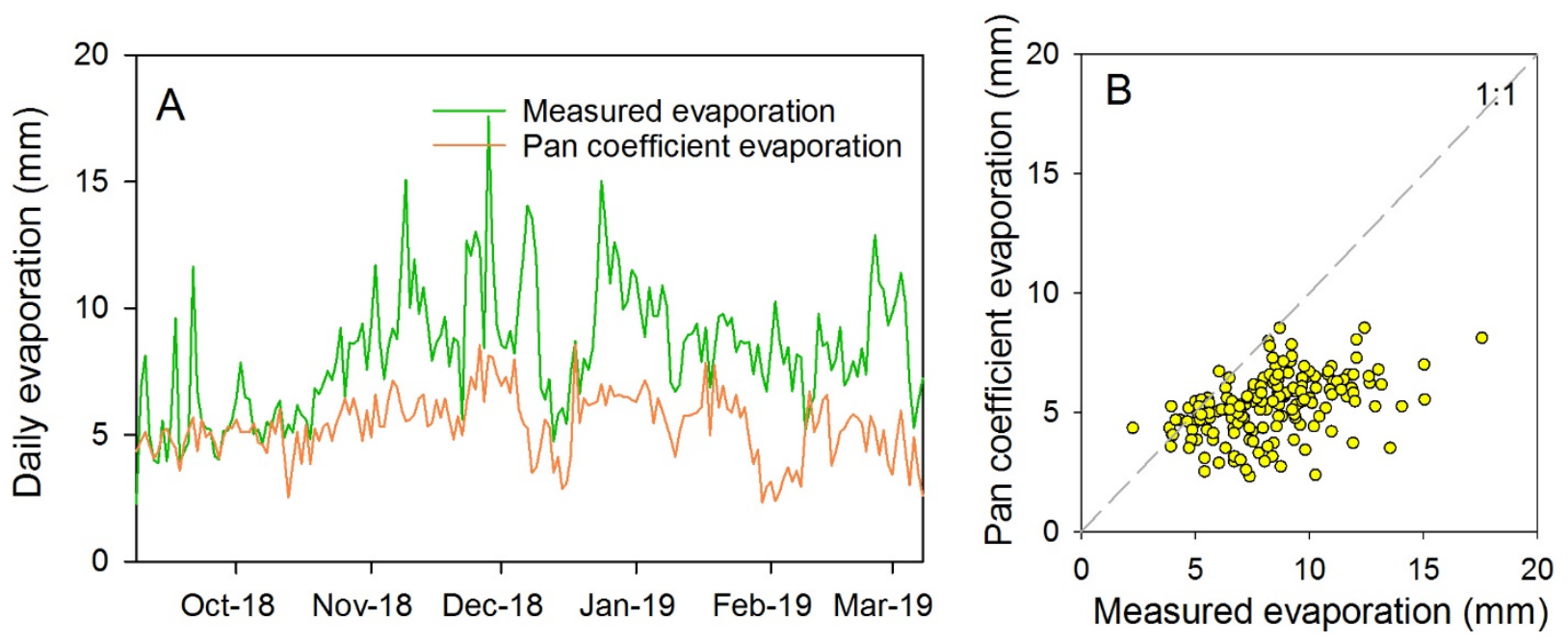

Figure 6 Comparison of measured evaporation rates to those predicted using the pan coefficient model. (a) Comparison of the time series; (b) Daily measured and modelled evaporation values plotted against each other 
The pan coefficient model is one of the most commonly used approaches for estimating evaporation from water bodies because of its simplicity and minimal data requirements. Despite the model's widespread use, many researchers have questioned the reliability of this approach (e.g. Adams et al. 1992; Hoy \& Stephens 1979; McJannet et al. 2013). A constant pan coefficient is often used (i.e. 0.7), but some studies have suggested that the coefficient should vary seasonally or monthly (e.g. Mulder 1997); however, Hoy \& Stephens (1979) showed that pan coefficients determined for individual sites actually varied across years and were therefore unreliable. Poor performance of the pan factor techniques for estimating water body evaporation has been reported in many other investigations that compare to measured values (e.g. Brutsaert \& Yeh 1970; Jensen et al. 1990; Kohler et al. 1955; Morton 1983; Tanny et al. 2008). The commonly reported reasons for this poor performance include the limited heat storage capacity of the pan, transfer of energy through evaporation pan walls and base, aerodynamic differences in the two water bodies in question and differences in lake turbidity and salinity. Additional uncertainty is often introduced by the distance between the pan evaporation measurement point and water body in question.

\subsection{CSIRO pit lake evaporation model}

Figure 7(a) shows a comparison of daily pit lake evaporation measurements and evaporation estimated using the CSIRO pit lake evaporation model over the six-month study period. The CSIRO pit lake evaporation model shows the same trends as the measured values, but daily values tend to underestimate those measured. Over the six-month period, the CSIRO pit lake model estimated that total evaporation loss was $1,174 \mathrm{~mm}$, which is $22 \%$ less than that measured onsite at Gilbert R6 $(1,505 \mathrm{~mm})$. A scatter plot of daily measured evaporation against daily evaporation estimated using the CSIRO pit lake model (Figure 7(b)) shows that the estimates are highly correlated with the measurements $\left(R^{2}=0.86\right)$. The high level of correlations suggests that the processes driving evaporation are being represented adequately but that the meteorological data being used to run the model may not be scaled appropriately. A comparison of temperature and humidity measurements at the land surface weather station and above the water showed very little variation; however, wind speed at the land surface was quite different from that over the lake and exhibited a trend that did not match the scaling approach used in the CSIRO pit lake evaporation model. Wind speed scaling in the CSIRO pit lake model assumes that wind speed is always reduced in a pit environment, but observations from Norwich Park Mine (Figure 8) show that wind speed at water level is typically greater than that at the land surface. It is now suspected that the narrow form of the coal mine pit acts to funnel the airflow and accelerate winds.
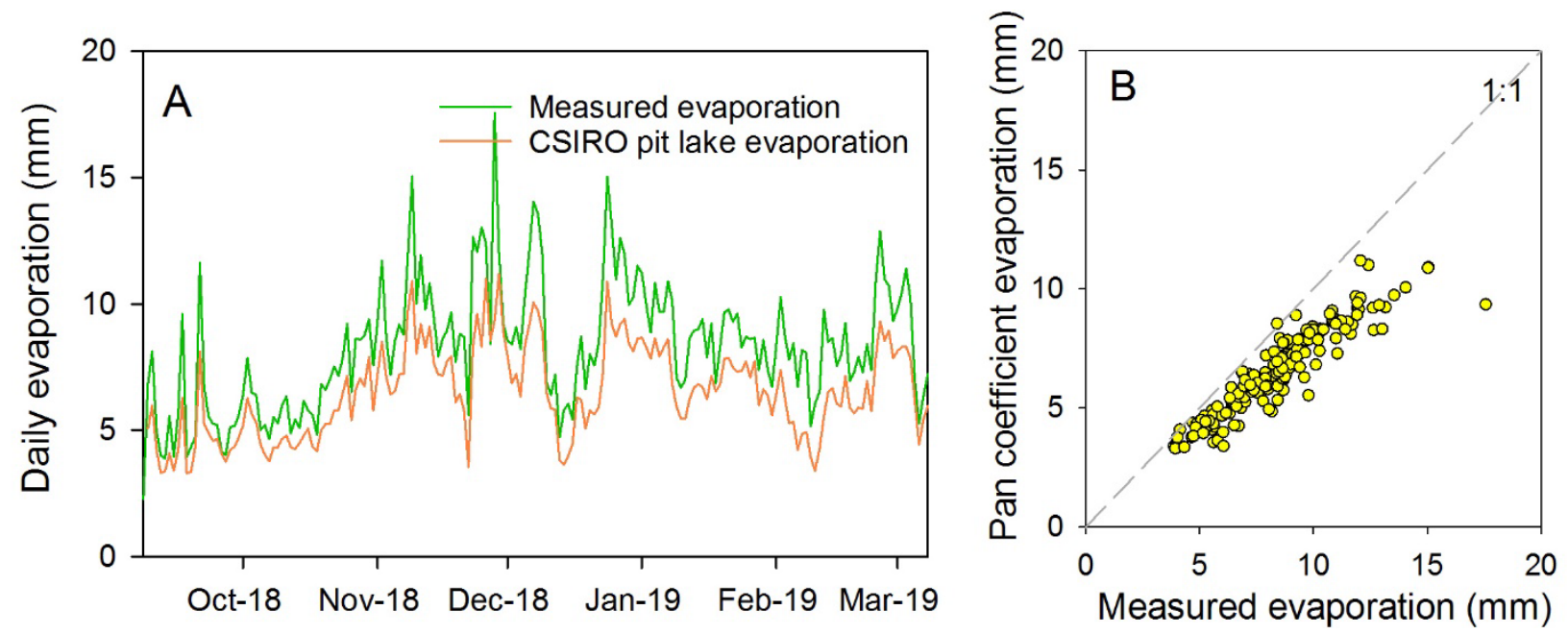

Figure 7 Comparison of measured evaporation rates with those predicted using the CSIRO pit lake evaporation model. (a) Comparison of the time series; (b) Daily measured and modelled evaporation values plotted against each other 


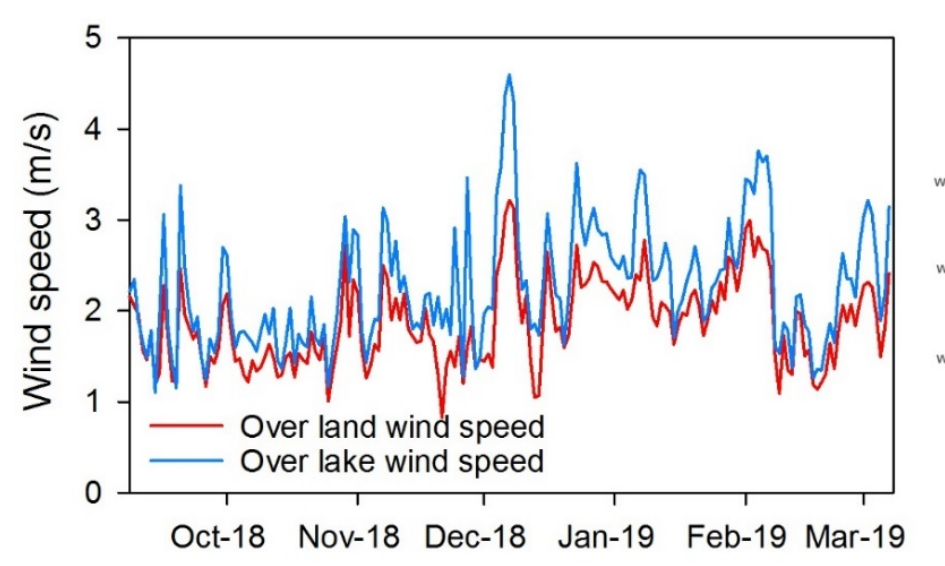

(a)

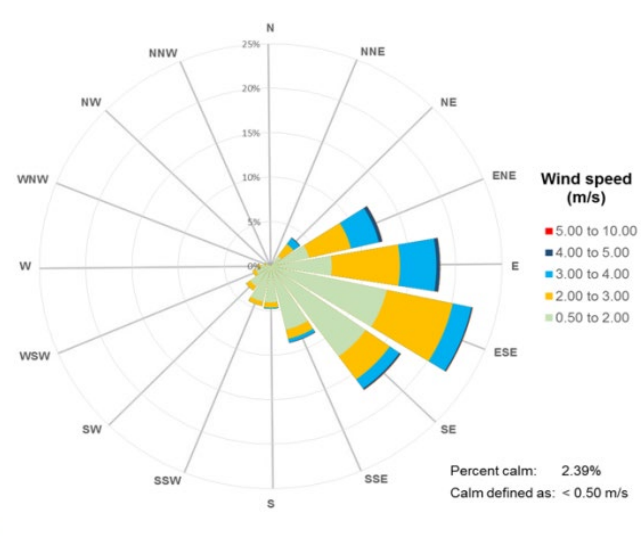

(b)

Figure 8 (a) Wind speed observed above the water surface and at the land surface at Gilbert R6; (b) Wind rose for top of the pit weather station

Wind speed scaling factors for Gilbert R6 ranged between 0.9 and 1.5 depending on wind direction; however, the wind rose for the site (Figure 8 ) shows that for $80 \%$ of the time the predominant wind direction was from east-northeast to southeast. Winds from this region are the strongest and are characterised by a wind speed scaling factor of 1.2. For simplicity, a $20 \%$ acceleration factor was applied to the time series of wind speed observed at the land surface before the CSIRO pit lake model was run once more. This is considered a simple correction until a more detailed analysis of wind speed differences over a longer period can be undertaken. Changing the wind speed scaling approach had a dramatic effect on evaporation prediction, with much improved model performance. The daily variation in evaporation was very well captured by the revised CSIRO pit lake model (Figure 9(a)) and total evaporation was 1,436 mm which is just $69 \mathrm{~mm}$ (or $5 \%$ ) less than that measured. The correlation between the two datasets was still strong $\left(R^{2}=0.78\right)$, and the data points clustered closely around the 1:1 line (Figure $9(\mathrm{~b})$ ). This analysis suggests that the wind scaling procedures developed for the CSIRO pit lake evaporation mine are not suitable for coal mine pits, because they behave differently from other pits, which are not as elongated. A methodology for scaling wind speed in coal mine pit lake environments now needs to be developed for better evaporation estimation, but we are encouraged by the model's performance once appropriate wind speed data were utilised. Future wind speed scaling approaches may need to incorporate a number of contributing factors, including pit dimensions (width, length and shape), water level relative to the land surface, and orientation to the prevailing wind.
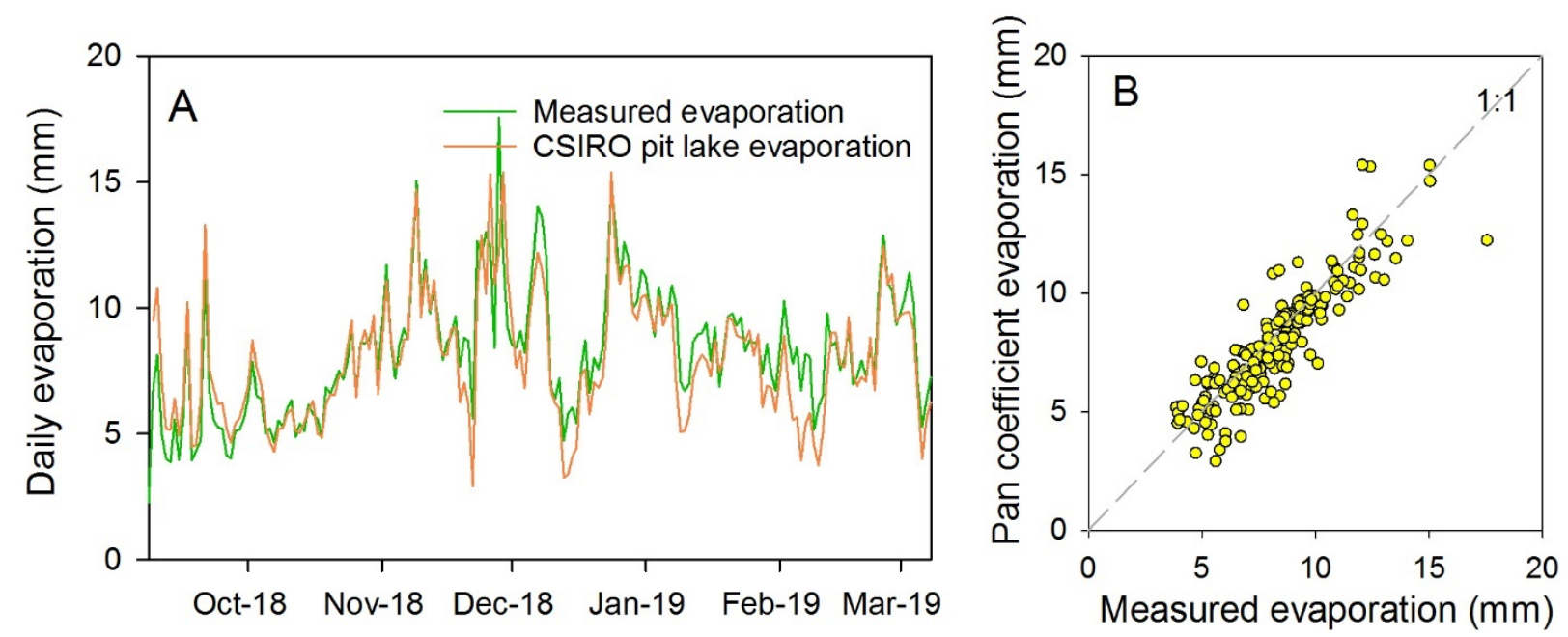

Figure 9 Repeat of Figure 7 but with wind speed in the CSIRO pit lake evaporation model scaled using local observation. (a) Comparison of the time series; (b) Daily measured and modelled evaporation values plotted against each other 


\section{Conclusion}

Evaporation measurements were taken at a pit lake at Norwich Park Mine over a six-month period from September 2018. Average evaporation during this period was $8.3 \mathrm{~mm} / \mathrm{d}$, which is high by international standards and reflects the hot and arid conditions experienced in this region. The evaporation measurements provided an excellent dataset by which to test the performance of two models for estimating pit lake evaporation. The first evaporation estimation approach was the pan coefficient model, which is used widely in the mining industry, and the second is a model developed by CSIRO in consultation with the mining industry to better represent the unique evaporation environment of a pit lake.

The pan coefficient model was shown to be a very poor predictor of daily evaporation. Other studies have had similar findings and have suggested that the potential reasons for the poor performance include differences in heat storage capacity, transfer of heat through evaporation pan walls and base, aerodynamic differences in the two water bodies in question, differences in lake turbidity and salinity, and effects of water body size on evaporation rate. While simple to apply with readily available datasets, the results of this study showed that the pan coefficient approach produced unreliable results, which would have resulted in significant underestimation of evaporation losses for water budget management purposes.

The CSIRO pit lake evaporation model showed the same trends in daily evaporation as measurements, but the model tended to consistently underestimate evaporation totals. Measurements and model predictions were highly correlated, suggesting that scaling of some of the meteorological inputs may be the likely cause of differences. Further investigation revealed that wind speeds at the lake level were in fact greater than those at the land surface; therefore, the currently defined wind scaling in the CSIRO pit lake evaporation model is inappropriate for coal mine environments. It is suspected that the long, narrow shape of the coal pits acts to funnel wind flow into the pit, thereby resulting in an acceleration of airflow. This is in contrast to the much broader pits, from which the wind speed scaling method was derived. Clearly, appropriate wind speed scaling approaches need to be defined for coal mine pits, and this will become the focus of upcoming measurements at Norwich Park Mine, with pits representing different aspects and depths being monitored for wind characteristics.

When appropriate wind speed scaling for Gilbert R6 was applied, the CSIRO pit lake model performance was excellent. Total predicted evaporation was within $5 \%$ of that measured, and daily trends were very well predicted. These results give confidence in achieving reliable evaporation estimates, once modified wind speed scaling approaches can be defined.

\section{Acknowledgement}

The authors thank Mike Bettison for helping to facilitate project initiation and Graham Moxham and his team at Norwich Park Mine for providing vital assistance with equipment installation and maintenance. This research project was funded by BHP Coal Pty Ltd.

\section{References}

Adams, J, Leibfried, R, Spoden, G \& Alderdice, L 1992, 'Surface water evaporation from mine pits in Minnesota', paper presented to the national meeting of the American Society for Surface Mining and Reclamation, Duluth, 14-20 June, https://doi.org/10.21000/JASMR92010268

Brutsaert, W \& Yeh, G-T 1970, 'Implications of a type of empirical evaporation formula for lakes and pans', Water Resources Research, vol. 6, pp. 1202-1208.

Calder, IR \& Neal, C 1984, 'Evaporation from saline lakes: a combination equation approach', Hydrological Sciences Journal, vol. 29, pp. 89-97.

Dalton, J 1802, 'Experimental essays on the constitution of mixed gases; on the force of steam or vapour from water and other liquids at different temperatures, both in a Torricellian vacuum and in air; on evaporation; and on the expansion of gases by heat', Memoirs of the Literary and Philosophical Society of Manchester, vols. 5-11, pp. 535-602.

De Bruin, HAR 1982, 'Temperature and energy balance of a water reservoir determined from standard weather data of a land station, Journal of Hydrology, vol. 59, pp. 261-274.

Edinger, JE, Duttweiler, DW \& Geyer, JC 1968, 'The response of water temperature to meteorological conditions', Water Resources Research, vol. 4, pp. 1137-1143. 
Finch, JW 2001, 'A comparison between measured and modelled open water evaporation from a reservoir in south-east England', Hydrological Processes, vol. 15, pp. 2771-2778.

Hoy, RD \& Stephens, SK 1979, Field Study of Lake Evaporation: Analysis of Data from Phase 2 Storages and Summary of Phase 1 and Phase 2, technical paper no. 41, Australian Water Resources Council, Canberra.

Jensen, ME, Burman, RD \& Allen, RG 1990, Evapotranspiration and Irrigation Water Requirements, ASCE manuals and reports on engineering practice no. 70, American Society of Civil Engineers, New York.

Johnson, SL \& Wright, AH 2003, Mine Void Water Resource Issues in Western Australia, hydrogeological record series, report HG 9. Western Australia Water and Rivers Commission, Perth.

Keijman, JQ 1974, 'The estimation of the energy balance of a lake from simple weather data', Boundary Layer Meteorology, vol. 7, pp. 399-407.

Kohler, MA 1952, Lake and Pan Evaporation. Water Loss Investigations, vol. 1, Lake Hefner Studies, technical report, circular no. 229. US Department of the Interior.

Kohler, MA, Nordenson, TJ \& Fox, WE 1955, Evaporation from Pans and Lakes, research paper 38, US Weather Bureau, Washington DC.

McJannet, D, Hawdon, A, Van Niel, T, Boadle, D, Baker, B, Trefry, M \& Rea, I 2017, 'Measurements of evaporation from a mine void lake and testing of modelling approaches', Journal of Hydrology, vol. 555, pp. 631-647, https://doi.org/10.1016/j.jhydrol.2017.10.064

McJannet, DL, Cook, FJ \& Burn, S 2013, 'Comparison of techniques for estimating evaporation from an irrigation water storage', Water Resources Research, vol. 49, pp. 1415-1428, https://doi.org/10.1002/wrcr.20125

Moore, I 1992, SRAD: Direct, Diffuse, Reflected Short Wave Radiation, and the Effects of Topographic Shading, Terrain Analysis Programs for Environmental Sciences (TAPES) Radiation Program Documentation, ANU Center for Resource and Environmental Studies, Canberra.

Morton, FI 1983, 'Operational estimates of lake evaporation', Journal of Hydrology, vol. 66, pp. 77-100.

Mulder, JC 1997, Queensland Lake and Aerial Evaporation, vol. 1, Report 000302.PR/2, Department of Natural Resources, Brisbane.

Munger, JW, Loescher, HW \& Luo, H 2012, 'Measurement, tower and site design considerations' in M Aubinet, T Vesala \& D Papale (eds), Eddy Covariance: A Practical Guide to Measurement and Data Analysis, Springer, Dordrecht, pp. 21-58.

Oroud, IM 1995, 'Effects of salinity upon evaporation from pans and shallow lakes near the Dead Sea', Theoretical and Applied Climatology, vol. 52, pp. 231-240.

Panin, GN \& Brezgunov, VS 2007, 'Influence of the salinity of water on its evaporation', Izvestiya, Atmospheric and Oceanic Physics, vol. 43, pp. 663-665, https://doi.org/10.1134/\$0001433807050143

Sivapalan, M 2005, Modelling the Evolution of Mount Goldsworthy Pit Lake, honours thesis. University of Western Australia, Perth.

Tanny, J, Cohen, S, Assouline, S, Lange, F, Grava, A, Berger, D, Teltch, B \& Parlange, MB 2008, 'Evaporation from a small water reservoir: direct measurements and estimates', Journal of Hydrology, vol. 351, pp. 218-229, https://doi.org/10.1016/j.jhydrol.2007.12.012

Wilson, J \& Gallant, J 2000, Secondary topographic attributes, in JP Wilson \& JC Gallant (eds), Terrain Analysis: Principles and Applications, John Wiley and Sons, New York, pp. 87-131.

Worley Parsons 2013, North Star Mine Pit Lake Assessment. Water and Solute Modelling, Water Solutions, Perth.

Zhan, J 2006, Kalgoorlie Consolidated Gold Mines Fimiston Pit Lake Water Balance Model, unpublished report, Barrick Gold Corporation, Perth. 
